Malaysian Journal of Social Sciences and Humanities (MJSSH)

Volume 4, Issue 7, November 2019

e-ISSN : 2504-8562

Journal home page:

www.msocialsciences.com

\title{
Interaksi Kepimpinan Perkongsian Mentor Melalui Motivasi Kerja Guru
}

\author{
Dadymus Upin Lonsiong1, Dg Norizah Binti Ag Kiflee@Dzulkifli1 \\ 1Fakulti Psikologi dan Pendidikan, Universiti Malaysia Sabah (UMS) \\ Correspondence: Dadymus Upin Lonsiong (dp1721050@student.ums.edu.my)
}

\begin{abstract}
Abstrak
Kertas konsep ini membincangkan interaksi gaya kepimpinan perkongsian 'mentor' terhadap tekanan kerja guru melalui motivasi kerja guru sekolah rendah di Sabah. Dalam proses mencapai matlamat untuk meningkatkan pencapaian murid, perkembangan dan pengukuhan kualiti guru perlu diberikan perhatian yang lebih lagi terutamanya motivasi dan pengurusan tekanan kerja di sekolah. Guru-guru juga memerlukan bantuan atau bimbingan daripada 'mentor' iaitu pegawai SISC+ untuk menjalankan pengajaran yang berkesan. Melalui bimbingan mentor tersebut, kualiti pendidikan yang lebih baik dapat dipelajari oleh murid-murid di sekolah rendah. Kepimpinan perkongsian terbentuk daripada faktor berorientasikan tugas seperti perancangan dan pengurusan serta penyelesaian masalah, dan faktor berorientasikan hubungan seperti sokongan dan pertimbangan serta pembangunan dan pementoran. Kepimpinan perkongsian semakin berkembang dan digunakan di dalam organisasi sebagai struktur berasaskan pasukan menggantikan struktur hierarki. Maka, motivasi kerja akan merangsang individu untuk mengambil tindakan tertentu untuk mendorong pekerja mencapai hasil yang berkesan. Motivasi bermula daripada keperluan, matlamat yang ingin dicapai dan haruslah mempunyai pertimbangan dan guru yang bermotivasi sentiasa berada dalam suatu ketegangan. Bagi mengurangkan tekanan ini, mereka harus lebih berusaha. Tekanan kerja adalah pengalaman yang berkait rapat dengan emosi guru tersebut terutamanya perasaan negatif dan berkaitan dengan kerja guru. Justeru itu, apabila guru boleh mengawal tekanan mereka, maka proses pengajaran dan pembelajarannya akan berjalan dengan lancar dan berkesan dalam mencapai matlamat yang telah ditetapkan oleh Kementerian Pendidikan Malaysia.
\end{abstract}

Kata kunci: motivasi kerja guru, kepimpinan perkongsian, tekanan kerja guru

\section{Mentor Shared Leadership Interaction Through Teacher's Work Motivation with the Teacher's Work Pressure}

\begin{abstract}
This concept paper discusses the interaction of mentor's shared leadership approach with the teacher's work pressure through the motivation of the primary school teachers in Sabah. In the process of achieving the goal of improving students' achievement, the development and improvement of teacher's quality need to be given more attention especially to motivate and work stress management in schools. Teachers also need the help or guidance from a mentor which is the School Improvement Specialist Coaches (SISC+) to conduct effective teaching. Through the guidance of the mentor, the quality of education learned by the students in primary school can be better. Shared leadership is made up of taskoriented factors such as planning, management and problem solving, and relationship-oriented factors such as support, consideration, development and mentoring. Shared leadership is growing and being
\end{abstract}


used within the organization as a team-based structure replacing the hierarchical structure. Therefore, work motivation will motivate individuals to take specific actions to encourage employees to achieve effective results. Motivation starts with needs, goals that are to be achieved and must be considerate, and motivated teachers are always in a tension. So, to reduce this pressure, they ned to work harder. Work stress is an experience that is closely related to the teacher's emotions and especially the negative feelings associated with the teacher's work. Therefore, when teachers are able to control their stress, their teaching and learning process will be smooth and effective in achieving the goals set by the Ministry of Education Malaysia.

Keywords: teacher's work motivation, shared leadership, teacher's work pressure

\section{Pengenalan}

Pendidikan merupakan satu wadah penting dalam pembangunan modal insan berkualiti yang dapat memacu Malaysia ke arah negara maju (Muhyiddin, 2015). Rancangan Malaysia Ke-11 (RMK-11) yang telah dipertanggungjawabkan kepada Kementerian Pendidikan Malaysia untuk memastikan negara "Memanfaatkan Bakat" dengan menghasilkan Modal Insan Minda Kelas Pertama yang mampu memanipulasi pengetahuan secara proaktif, kreatif dan inovatif. modal insan berkualiti yang dibentuk melalui sistem pendidikan negara bukan sahaja mampu memenuhi tuntutan pembangunan ekonomi, tetapi juga mempunyai penghayatan nilai dan adab yang tinggi.

Sehubungan itu, melalui sistem pendidikan tersebut, wujud satu program yang membantu guru-guru di sekolah iaitu program Jurulatih Pakar Pembangunan Sekolah atau School Improvement Specialist Coaches (SISC+). Program ini adalah untuk membimbing guru-guru di sekolah dari aspek pedagogi, Pentaksiran Berasaskan Sekolah (PBS) dan Kurikulum Standard Sekolah Rendah (KSSR) dan sekaligus melahirkan golongan pendidik berkemahiran tinggi selaras dengan perkembangan semasa (Fadzly Izab, 2015). Pegawai-pegawai SISC + ini akan dianggap sebagai pemimpin kepada guru-guru yang dilatih di sekolah-sekolah setiap daerah dalam sesebuah negeri.

Kepimpinan adalah kemampuan untuk menguruskan perubahan dalam organisasi. Persekitaran pemimpin sekarang adalah agak berbeza kerana gaya kepimpinan masa kini memerlukan proses penyesuaian, supaya perubahan dapat direalisasikan ke arah perkembangan organisasi yang cemerlang (Anis Salwa dan Siti Noor, 2018). Pemimpin mesti mengadaptasikan gaya-gaya kepimpinan yang terbaik bagi mengubah keadaan dan memberikan tumpuan terhadap keperluan pembangunan kepimpinan yang meningkatkan fleksibiliti dalam gaya dan strategi kepimpinan, malahan sudah tiba masanya untuk memberi ruang kepada pembangunan kepimpinan perkongsian (Hallinger,P., 2011).

Persepsi masyarakat umum, tugas mendidik merupakan sesuatu yang mudah. Namun begitu, hakikatnya ia adalah sukar dan mencabar. Tugas guru bukan sekadar mendidik pelajar supaya cemerlang dalam peperiksaan sahaja tetapi juga memastikan pelajar mempunyai pengetahuan yang luas dalam pelbagai ilmu (Shalini dan Mohd. Jasmy, 2018). Masyarakat zaman sekarang menuntut agar guru menjalankan tugas mendidik dengan lebih berkesan dan menjadi contoh yang baik kepada pelajar dalam masa yang sama. Guru yang berada dalam sistem pendidikan, sama ada baru atau telah lama berkhidmat dalam kerjaya tersebut, perlu sentiasa melengkapi diri mereka dengan pengetahuan dan kemahiran baru yang berkaitan dengan perubahan kurikulum, penilaian, integrasi teknologi dan sumber untuk memenuhi keperluan pendidikan di abad ke-21 (Raja dan Lim, 2017). Guru dikehendaki mengikuti perkembangan dunia pendidikan yang pesat dan memenuhi permintaan sistem pendidikan yang sentiasa berubah.

Semua cabaran dalam dunia pendidikan ini akan memberikan kesan terhadap tingkah laku guru dan perubahan tingkah laku ini wujud akibat tekanan kerja yang dihadapi oleh guru. Tugas guru sekolah yang berhadapan dengan pelbagai ragam murid amat memerlukan kestabilan mental dan emosi supaya mereka dapat bekerja dengan lebih baik. Secara umumnya, tahap tekanan kerja yang rendah dan sederhana memberikan kebaikan kepada seseorang individu kerana individu tersebut akan memberi 
perhatian terhadap tugasnya. Manakala tahap tekanan kerja yang tinggi akan mengurangkan prestasi kerja dan menjejaskan kesihatan. Malah tahap tekanan kerja yang tinggi dipercayai menjadi antara punca kepada masalah 'burnout' dan berhenti kerja awal (Zarapi dan Zuraidah, 2015).

Oleh itu, dalam menggalas tanggungjawab menjadi pemain utama bidang pendidikan, guru seharusnya mempunyai semangat juang yang tinggi supaya dapat beradaptasi dengan perubahan yang sangat pantas berlaku supaya dapat membawa diri dalam dunia moden yang berkembang pesat. Jika cabaran dan perubahan ini tidak dapat ditangani dengan baik, maka guru akan berasa tertekan dan mungkin mengalami masalah mental.

\section{Literatur Kajian}

\section{Interaksi Kepimpinan Perkongsian Mentor}

Kepimpinan perkongsian dianggap sebagai suatu proses kepimpinan, kerjasama atau fenomena yang melibatkan pasukan yang saling mempengaruhi satu sama lain, membahagikan tugas secara kolektif apabila tanggungjawab tidak diturunkan kepada seorang pemimpin pusat tunggal (Michael, 2010). Kepimpinan perkongsian adalah proses yang dinamik dan pengaruh interaktif di kalangan individu dalam kumpulan yang bertujuan untuk memimpin satu sama lain kepada pencapaian matlamat kumpulan atau organisasi atau kedua-duanya (Avolio et.al, 2009).

Mentor merupakan individu berpengaruh dalam persekitaran kerja anda dan biasanya adalah ahli yang lebih senior daripada anda dalam organisasi atau profesion, individu yang mempunyai pengalaman dan pengetahuan yang luas dan seseorang yang komited terhadap peningkatan dan menyokong kerjaya anda (Forret dan de Janasz, 2005). Dana et.al (2011), menyatakan mentor adalah seseorang, selain pengurus anda atau rakan sekerja yang terdekat, yang memberi anda nasihat teknikal atau kerjaya, bimbingan atau maklumat secara tidak rasmi. Interaksi kepimpinan perkongsian mentor yang dimaksudkan adalah kebolehan pimpinan pegawai SISC + di setiap daerah untuk mempengaruhi atau saling mempengaruhi guru-guru di daerah tersebut dalam mencapai matlamat yang telah ditetapkan. Kepimpinan perkongsian tersebut haruslah melibatkan guru-guru lain dalam membuat keputusan yang sesuai untuk kepentingan matlamat yang ingin dicapai.

Michael (2010) telah menyatakan bahawa kepimpinan perkongsian telah wujud sejak zaman purba lagi melalui sistem pemerintahan Republik Rom dan berjaya digunakan lebih daripada empat abad. Struktur kepimpinan perkongsian ini begitu berkesan sehingga meluas dari peringkat bawahan ke kedudukan yang tertinggi iaitu konsul. Walau bagaimanapun, melalui rujukan sejarah-sejarah lalu, kebanyakkan organisasi telah diketuai oleh seorang pemimpin utama sahaja menggunakan sistem hierarki (Wood, 2005).

O'Toole (2001) mencadangkan sifat kepimpinan bukan sahaja bersifat individu tetapi juga bersifat institut atau kelompok. Kepimpinan perkongsian semakin berkembang dan digunakan di dalam organisasi sebagai struktur berasaskan pasukan mengantikan struktur hierarki (Avolio et.al, 2009). Ini menunjukkan zaman telah berubah dan corak kepimpinan haruslah berubah. Dahulunya, "trend" pengaruh kuasa yang dipegang oleh seorang pemimpin, kini telah berubah dan berkembang menuju kepada kepimpinan yang tertinggi dalam sesebuah organisasi korporat.

Selain itu, Yukl (2006) menyatakan individu yang mengamalkan pendekatan kepimpinan perkongsian dapat memahami apa dan bagaimana sesuatu keputusan penting dilakukan melalui proses interaktif dalam organisasi. Ini kerana ia akan melibatkan individu yang berasingan dan saling mempengaruhi satu sama lain untuk mencapai keputusan. Namun begitu, di sebalik pemahaman "many minds are better than one," kepimpinan perkongsian masih sukar diamalkan dalam persekitaran sekolah. Ini disebabkan oleh perbezaan konsep antara pentadbiran dan kepimpinan (Ronald, 2008).

Kedua-dua konsep ini telah banyak diberikan perhatian dalam kajian-kajian pengkaji sebelum ini bagi menentukan dan membezakan kedua-dua konsep tersebut (Bennis dan Nanus, 1985; Owens, 1995; 
Yukl, 1998; Coleman dan Earley, 2004). Namun, perbezaan ini sering kali diabaikan dalam sesuatu organisasi seperti sekolah. Sebagai contoh, dalam merancang pengurusan tapak bagi kerja pasukan atau pemimpin di kalangan guru. Semasa penetapan tapak pengurusan kerja, perbincangan akan menjadi tidak relevan kerana keputusan pentadbiran seperti jadual, pembangunan kurikulum, dan proses akreditasi akan memakan masa yang banyak dan menjadikannya kurang diminati oleh guru. Guru secara rela hati melepaskan peranan tadbir urus mereka supaya mereka dapat menumpukan masa dan usaha mereka di dalam kelas (Sinéad Brennan, 2016). Guru mengembalikan tugas pentadbiran kepada pihak pentadbir seperti guru besar dan penolong-penolong kanan yang telah dilepaskan daripada tanggungjawab kelas untuk mempunyai masa yang diperlukan bagi menghadiri tugas pentadbiran.

\section{Motivasi Kerja Guru}

Bambang (2013) menyatakan motivasi adalah sebab atau dorongan yang berada dalam diri individu yang menyebabkan mereka melakukan sesuatu. Motivasi kerja merupakan keinginan yang terdapat pada seseorang individu dan merangsangnya untuk melakukan sesuatu tindakan. Dorongan tersebut timbul pada diri seseorang secara sedar atau tidak sedar untuk melakukan sesuatu tindakan dengan tujuan tertentu (Mohd. Zaki, 2009). Motivasi kerja guru yang dimaksudkan adalah motivasi kerja guru sekolah rendah untuk mengajar dan melaksanakan tugas mereka yang datang daripada dorongan dalaman seperti minat dan kepuasan diri atau daripada dorongan luaran seperti anugerah pencapaian dan hukuman tindakan tatatertib.

Syarifah et. al. (2013), menyatakan pekerja yang bermotivasi sentiasa berada dalam suatu ketegangan dan untuk mengurangkan tekanan ini, mereka harus lebih berusaha. Apabila tekanan yang dihadapi adalah lebih tinggi, maka lebih tinggi usaha mereka. Jika usaha ini diarahkan kepada keperluan kepuasan, secara tidak langsung ia akan mengurangkan tekanan yang dihadapi. Dalam usaha memotivasikan pekerja untuk mencapai prestasi terbaik dan menggunakan sumber yang terhad dengan keberkesanan yang maksimum, perlu untuk menyediakan dan memenuhi minat peribadi seseorang itu (Zamani \& Talatapeh, 2014).

Selain itu, produktiviti secara tidak langsung akan meningkat dan objektif keseluruhan pengurusan akan dicapai. Russ (2010); Miao et. al (2007), Orpen (1997) mendapati pekerja yang mempunyai motivasi kerja yang tinggi akan sentiasa menjalankan kerja dengan kelakuan yang terbaik. Guru memainkan peranan penting dalam proses pembelajaran murid, maka motivasi para guru amat penting kerana mempunyai kesan langsung kepada murid (Alam \& Farid, 2011). Disebabkan itu, guru haruslah mempunyai motivasi kerja yang tinggi untuk menjalankan tanggungjawab mereka dengan baik.

Justeru, keinginan guru melalui faktor motivasi seperti pengiktirafan, pencapaian, peluang pembangunan dan kenaikan pangkat, tanggungjawab serta kerja yang bermakna, dilihat mampu mempengaruhi dan mendorong kepada kepuasan kerja yang positif untuk meningkatkan pencapaian murid dalam bilik darjah (Boyle, 2014). Pelbagai faktor motivasi mempengaruhi keberkesanan kerja guru-guru sekolah bagi menaikkan prestasi dalam usaha untuk meningkatkan keberkesanan institusi (Rasheed et.al., 2010).

\section{Tekanan Kerja Guru}

Tekanan kerja merujuk kepada perubahan emosi yang tidak menyenangkan seperti ketegangan, kekecewaan dan kemarahan hasil dari pekerjaan. Keadaan pekerjaan yang buruk, salah laku pelajar, kekurangan sumber untuk mengajar, beban tugas bukan mengajar dan sikap pelajar terhadap pelajaran merupakan antara punca tekanan kerja guru kerap berlaku. (Mazlina, 2014). Tekanan kerja guru yang dimaksudkan oleh pengkaji adalah tekanan kerja guru-guru sekolah rendah. Tekanan kerja adalah pengalaman yang berkait rapat dengan emosi guru tersebut terutamanya perasaan negatif dan berkaitan dengan kerja guru. Antara emosi yang tidak menyenangkan dialami oleh guru adalah seperti perasaan kecewa, bimbang, marah, berdukacita, tegang, sedih dan sebagainya yang disebabkan oleh bidang tugas atau tanggungjawab mereka. 
Suatu tanggapan bahawa tugas guru sekolah rendah adalah mudah telah lama wujud di kalangan masyarakat. Mereka menganggap tugas guru hanya mengajar di dalam kelas dan tidak melakukan apaapa selain daripada itu. Hakikatnya, guru memegang pelbagai tugas berlainan di sebalik tugas hakiki mereka mengajar murid-murid. Kamaruzaman (2007), Ooi Chew Hong dan Aziah (2015), dan Raja Maria (2011) menyatakan guru kini banyak diberi tugas-tugas lain seperti warden, jurulatih, tugastugas pengkeranian dan menyebabkan mereka terbeban terutamanya tugas-tugas pengkeranian. Guruguru yang tertekan dengan bebanan kerja yang banyak akan mengalami masalah emosi.

Penyelarasan dari segi pengagihan tugas guru di peringkat pihak pentadbir sekolah amatlah penting agar guru dapat mengutamakan tugas hakikinya iaitu mengajar murid di dalam kelas dan bukannya tugasan perkeranian. Sekiranya tiada perbincangan di kalangan guru-guru penolong kanan dalam mengagihkan tugas-tugas khas kepada guru, agihan tugas yang tidak seimbang di kalangan guru-guru akan berlaku (Raedah, 2013). Guru tidak mampu melaksanakan masa pengajaran yang optimum kerana tugas guru meliputi bidang akademik dan bukan akademik. Isu yang berkaitan dengan ruang masa yang diperuntukkan dan agihan tugas kepada guru yang tidak seimbang kerap dibincangkan (Fatimah dan Khairudin, 2008).

Guru tidak mempunyai masa untuk menyertai pengurusan peranan pentadbiran bersama secara berkesan (Ronald,2008). Walaupun ramai guru yang sanggup berkongsi masa dan bakat mereka dalam membentuk budaya persekitaran sekolah, menganalisis keputusan akreditasi atau menetapkan jadual secara kolaboratif, namun ia adalah tidak produktif dan memuaskan dalam penggunaan masa guru. Tugas pentadbiran adalah lebih baik diserahkan kepada pentadbir. Peranan seperti pengurusan "bas, buku, tandas" bukanlah peranan kepimpinan tetapi adalah peranan pentadbiran.

Anis (2018) menyatakan tekanan kerja terhadap guru memberikan impak kepada hubungan peribadi dan kesihatan fizikal. Tekanan kerja yang dialami golongan guru ini akan meletakkan mereka dalam keadaan murung, kecewa, bimbang dan mengalami tekanan jiwa. Akibatnya guru tidak akan dapat memberikan sepenuh komitmen terhadap kerjaya mereka. Tekanan yang berterusan akan menjejaskan kualiti pendidikan dan profesion guru seterusnya akan menjejaskan usaha ke aras mewujudkan masyarakat berilmu pada masa hadapan. Secara tidak langsung akan menjejaskan usaha negara mencapai matlamat meningkatkan tahap kecemerlangan mutu pendidikan (Sapora Sipon, 2007).

Selain itu, tekanan kerja merupakan salah satu faktor yang mempengaruhi prestasi kerja guru yang akhirnya akan memberi kesan terhadap pencapaian murid. Peranan guru dan pemimpin sekolah adalah sangat kompleks, pelbagai dimensi dan prestasi kerja dipengaruhi oleh faktor termasuk mewujudkan dan menjaga persekitaran kerja yang sihat dan kreatif. Peluang latihan dan pembangunan kerjaya yang efektif dan sistematik, penglibatan guru dalam membuat keputusan dan keadaan kerja yang lebih baik adalah faktor yang membantu guru menjalankan kerja, meningkatkan kepuasan kerja dan mengurangkan tekanan emosi (Anastasiou \& Papakonstantinou, 2014).

\section{Interaksi Kepimpinan Perkongsian Mentor melalui Motivasi Kerja dengan Tekanan Kerja Guru Sekolah Rendah}

Kepimpinan adalah salah satu faktor yang kritikal dan penting dalam meningkatkan prestasi organisasi (Riaz, 2010). Ibrahim dan Chua (2017) menyatakan bahawa kepimpinan adalah hala tuju atau membangunkan visi masa depan bersama-sama dengan strategi yang diperlukan untuk menghasilkan perubahan demi mencapai sesuatu wawasan. Oleh itu, bagi organisasi seperti sekolah, pengaruh kepimpinan dan kecekapan pemimpin amatlah penting dalam menentukan kejayaan sekolah-sekolah di bawah pimpinannya. Bagi pembentukan organisasi di peringkat daerah yang berkesan, ia bergantung kepada kepimpinan pegawai SISC + tersebut. Sesebuah organisasi seperti komuniti pendidik profesional yang terdiri daripada guru-guru berbeza latar belakang harus dibimbing dengan teliti agar segala tingkah laku mereka dapat diselaraskan.

Idea bahawa kepimpinan dapat dikongsi oleh pelbagai orang dalam unit kerja atau kumpulan adalah lanjutan bagi memperkasakan pandangan kepimpinan dan konsep kepimpinan diri yang berkaitan 
(Kathi et.al, 2007). Kepimpinan yang dikongsi merujuk kepada dinamik dan proses pengaruh interaktif di kalangan anggota yang memimpin satu sama lain untuk membantu organisasi (Pearce \& Conger,2003). Kepimpinan berdasarkan proses pengaruh bersama amat relevan untuk mempengaruhi konteks kerja yang melibatkan kerja berpasukan. Pelbagai ahli pasukan diberi kuasa untuk menjalankan kepimpinan dalam pelbagai cara di masa yang berlainan seperti keadaan yang diperlukan dan dengan itu menghilangkan beban kepimpinan daripada pemimpin yang ditetapkan.

Kajian daripada pengkaji lepas telah mencadangkan bahawa prestasi pasukan kerja dapat ditingkatkan dengan ketara melalui perkongsian kepimpinan (Avolio et.al, 2009; Hooker \& Csikszentmihalyi, 2003; Pearce et.al, 2004; Shamir \& Lapidot,2003). Melalui pemupukan pendekatan perkongsian berterusan dengan kepimpinan, pemimpin bukan sahaja dibebaskan daripada tuntutan sebagai sumber pengaruh dan berpengetahuan yang utama tetapi ahli bawahan atau pekerja yang terdiri daripada latar belakang, latihan dan pengalaman yang berbeza lebih bebas untuk meningkatkan dan memimpin mengikut keperluan proses kerja. Tekanan peranan pemimpin rasmi juga dapat dikurangkan melalui pembangunan amalan berterusan dalam proses berkongsi. Ia juga meningkatkan pengawalan jangka panjang dalam sistem untuk memenuhi permintaan persekitaran yang berubah.

Eyal dan Roth (2011) menyatakan pemimpin memainkan peranan penting terhadap motivasi guru dan gaya kepimpinan yang berbeza adalah berhubung kait dengan kepelbagaian sumber motivasi guru yang berlainan. Pernyataan berikut dapat dikaitkan dengan pemimpin-pemimpin lain dalam bidang pendidikan, khususnya pegawai SISC + di setiap daerah. Motivasi yang terhasil daripada pengaruh kepimpinan dapat memberi kesan yang ketara dalam penglibatan pekerja (Hidayat,2016). Gaya kepimpinan yang menggalakkan penglibatan guru-guru mampu mendorong kepada tahap motivasi yang lebih tinggi (Mehta et.al., 2003). Perubahan tingkah laku pekerja dalam menjalankan kerja itu akan mempunyai impak yang tinggi supaya pekerja dengan motivasi kerja yang tinggi boleh menunjukkan prestasi yang lebih baik.

Ramai guru menganggap kepimpinan perkongsian menyebabkan mereka terbeban dengan tugas-tugas pentadbiran (Ronald,2008). Ini menyebabkan mereka tertekan. Kepimpinan perkongsian melibatkan guru-guru lain dalam mencapai sesuatu keputusan atau merangka sesuatu pelan. Ia menambah beban tugas pentadbiran kepada mereka seperti merangka, menganalisis, dan menjalankan program bagi mencapai matlamat pendidikan yang telah ditetapkan. Selain itu, guru sering diminta untuk menanggung peranan pentadbiran seperti penyeliaan atau penilaian rakan sekerja, perkembangan guru, peningkatan penglibatan ibu bapa dan semua ini sering dilakukan dengan masa pelepasan daripada tugas-tugas di kelas yang minimum atau tiada. Pemimpin atau guru besar melihat guru yang memegang jawatan tersebut sebagai tugas sementara. Guru menjadi keliru dengan peranan pentadbiran dan kelas mereka. Kepuasan hanya timbul apabila pemimpin dan ahli yang lain beroperasi dalam lingkungan organisasi yang sihat.

Motivasi merupakan tahap atau usaha yang dilakukan terhadap pembahagian tugas dan aktiviti yang berkenaan dengan peranan dan skop kerja (Mehta et al., 2003). Guru-guru akan lebih menglibatkan diri dalam tugas-tugas tersebut sekiranya mereka mempunyai dorongan dan minat terhadap peranan atau tanggungjawab tersebut. Sekaligus meningkatkan motivasi kerja guru tersebut. Tekanan kerja yang dialami oleh guru akan berkurangan sekiranya motivasi mereka berada pada tahap yang tinggi.

\section{Kesimpulan}

Suatu perubahan dalam corak kepimpinan di dunia pendidikan perlu dilakukan selaras dengan perubahan masa. Suatu kepercayaan daripada masyarakat telah diberikan kepada sistem pendidikan negara untuk membentuk modal insan yang seimbang mengikut peredaran masa. Justeru, kepimpinan mentor dalam membimbing guru-guru di bawah bimbingan mereka amatlah penting bagi merealisasikan tuntutan masyarakat. Bimbingan yang betul dapat membentuk acuan bagi modal insan seimbang yang ingin dicapai melalui pendidikan negara. Walaubagaimanapun, mentor haruslah mengambil kira beban tugas dan tekanan yang dialami oleh guru sekolah rendah dalam mencapai matlamat tersebut. Kebijaksanaan mentor dalam memotivasikan guru-guru dan membuat keputusan 
berdasarkan kepimpinannya adalah sangat penting untuk mencapai aspirasi dan sistem pendidikan yang berkesan.

\section{Rujukan}

Alam, M. T., \& Farid, S. (2011). Factors affecting teachers motivation. International Journal of Business and Social Science, 2(1), 298-304.

Anastasiou, S., \& Papakonstantiou, G. (2014). Factors affecting job satisfaction, stress and work performance of secondary education teachers in Epirus, NW Greece. International Journal of Management in Education, 8(1), 37-53.

Anis Salwa Abdullah, Siti Noor Ismail. (2018). Interaksi Kepimpinan Perkongsian dan Kepimpinan Sahih Guru Besar Terhadap Motivasi dan Tekanan Kerja Guru. Jurnal Kepimpinan Pendidikan, $5(1), 16-32$.

Avolio, B.J., Walumbwa, F.O., \& Weber, T.J. (2009). Leadership: Current theories, research, and future directions. Annual Review of Psychology, 60, 421-449.

Bambang Kristianto Wibowo, Dosen Tetap ASM Santa Maria. (2013). Pengaruh Komunikasi Internal, Motivasi Kerja Dan Loyalitas Terhadap Kinerja Guru Sekolah Menengah Kejuruan Negeri Rumpun Bisnis Sekota Semarang. Jurnal STIE Semarang, 5(2), 36-47.

Bennis, W. \& Nanus. (1985). Leaders: The Strategies for Taking Charge. New York: Harper and Row.

Boyle, T. P. (2014). High school teachers' and administrators' perceptions of teacher motivation factors. Kennesaw, Georgia: Kennesaw State University.

Chiu, C. C., Owens, B. P., \& Tesluk, P. E. (2016). Initiating and utilizing shared leadership in teams: The role of leader humility, team proactive personality, and team performance capability. Journal of Applied Psychology, 101, 1705-1720.

Coleman, M. \& Earley, P. (2004). Leadership and Management in Education. United Kingdom: Oxford University Press.

Dana L. Haggard, Thomas W. Dougherty, Daniel B. Turban, James E. Wilbanks. (2011). Who Is a Mentor? A Review of Evolving Definitions and Implications for Research. Journal of Management, 37(1), 280-304.

Eyal, O., \& Roth, G. (2011). Principals' leadership and teachers' motivation: Self-determination theory analysis. Journal of Educational Administration, 49(3), 256-275.

Fadzly Izab. (20 Jun, 2015). Utusan Online. Muat turun daripada m.utusan.com.my: http://m.utusan.com.my/berita/nasional/sisc-bantu-lahir-guru-berkemahiran-tinggi-murid-kreatif1.104986

Fatimah Saleh, Khairudin Puat. (2008). Ketirisan Waktu Pengajaran Guru Di Sekolah. Pengurusan \& Pentadbiran, 8(1), 65-75.

Forret, M., \& de Janasz, S.C. (2005). Perceptions of an organization's culture for work and family: Do mentors make a difference?Career Development International, 10(6/7), 478-492.

Hallinger,P. (2011). A Review of Three Decades of Doctoral Studies Using the Principal Instructional Management Rating Scale: A Lens on Methodological Progress in Educational Leadership. Educational Administration Quarterly, 47(2), 271-306.

Hidayat, S. (2016). The Authentic Leadership Is Source Of Intrinsic Motivation In Work Engagement With Moderating Role Of Overall Trust (Cognitive And Affective Trust). International Research Journal of Management Sciences, 4(3), 195-201. Retrieved from http://www.irjmsjournal.com

Hooker, C., \& Csikszentmihalyi, M. (2003). Flow, creativity, and shared leadership: Rethinking the motivation and structuring of knowledge work. In C. P. (Eds.), Shared leadership: Reframing the hows and whys of leadership (pp. 217-234). Thousand Oaks: C.A : Sage Publications.

Ibrahim Jari, Chua Yan Piaw. (2017). Pengaruh Perilaku Kepimpinan Pengetua Ke Atas Tekanan Kerja Guru Sekolah Menengah Di Melaka. Educational Leader (Pemimpin Pendidikan), 5, 5: 5974.

Kamaruzaman Kamaruddin. (2007). Tekanan Kerja Dalam Kalangan Guru Sekolah Menengah. Jurnal Kemanusian, 5(2), 104-118. 
Kathi J. Lovelace, Charles C. Manz, Jose C. Alves. (2007). Work Stress and Leadership Development: The Role of Self-leadership, Shared Leadership, Physical Fitness and Flow in Managing Demands and Increasing Job Control. Human Resource Management Review, 17, 374-387.

Mazlina Bt. Sulaiman. (2014). Hubungan Tekanan Dengan Komitmen Dan Kepuasan Kerja Dalam Kalangan Guru Program Pendidikan Khas Integrasi Bermasalah Pembelajaran Di Empat Buah Sekolah Rendah Daerah Pontian. Skudai. Johor: Universiti Teknologi Malaysia.

Mehta, R., Dubinsky, A. J., \& Anderson, R. E. (2003). Leadership style, motivation and performance in international marketing channels. European Journal of Marketing, 37(4), 50-85.

Miao, C. Fred \& Kenneth R. Evans. (2007). The Impact of Salesperson Motivation on Role Perceptions and Job Performance- A Cognitive and Affective Perspective. Journal of Personal Selling \& Sales Management, 27, 89-101.

Michael D. Kocolowski. (2010). Shared Leadership : Is it Time for a Change? Emerging Leadership Journeys, 3(1), 22-32.

Mohd. Zaki Bin Ahmad. (2009). Motivasi Dalam Pembelajaran Bahasa Arab di Sekolah Menengah Agama. Kuala Lumpur: Universiti Malaya.

Ooi Chew Hong, Aziah Ismail. (2015). Sokongan Pihak Pengurusan Sekolah Terhadap Tekanan Kerja Guru Di Sekolah Kebangsaan dan Sekolah Jenis Kebangsaan Cina. Jurnal Kepimpinan Pendidikan, 2(2), 42-57.

Orpen, C. (1997). The Effects of Formal Mentoring On Employee Work Motivation, Organizational Commitment and Job Performance. The Learning Organization, 4(2), 53-60.

O'Toole, J. (2001). When leadership is an organizational trait. In G. M. W.Bennis, The Future of Leadership (pp. 158-176). San Francisco: Jossey-Bass.

Pearce, C. L., \& Conger, J. A. (2003). Shared Leadership: Reframing the hows and whys of leadership. Thousand Oaks: C.A: Sage.

Pearce, C. L., Yoo, Y., \& Alavi, M. (2004). Leadership, social work and virtual teams: The relative influence of vertical vs. shared leadership in the nonprofit sector. In R. R.-O. (Eds.), Nonprofit leadership (pp. 180-203). San Francisco: Jossey Bass.

Raedah Binti Md. Amin. (2013). Pengurusan Pengajaran dan Pembelajaran Sekolah Rendah Kebangsaan Di Zon Bandar Daerah Kota TInggi. Johor Bahru: Universiti Teknologi Malaysia.

Raja Maria Diana Bt. Raja Ali. (2011). Faktor-faktor yang Mendorong Tekanan Kerja (Stres) di Kalangan Guru-Guru Sekolah Menengah di Daerah Pasir Putih. Kuala Lumpur: Open Universiti Malaysia.

Raja Nor Safinas, Lim Bee Yoke. (7 Jun, 2017). Teachers must embrace lifelong learning. Retrieved from New Straits Times: https://www.nst.com.my/education/2017/06/246592/teachers-mustembrace-lifelong-learning

Rasheed, M. I., Aslam, H. D., \& Sarwar, S. (2010). Motivational issues for teachers in higher education: A critical case of IUB. Journal of Management Research, 2(2), 1-24.

Riaz,A. (2010). Role of transformational and transactional leadership on job satisfaction and career satisfaction. Business and Economic Horizons (BEH), 1(1), 29-38.

Ronald Lindahl. (2008). Shared Leadership: Can It Work in School? The Educational Forum, 72, 298307.

Russ Travis L. (2010). An Exploratory Study of And Experiential Change Program's Impact on Participants' Affective Outcomes. Leadership \& Organization Development Journal, 32(5), 493509.

Sapora Sipon. (2007). Keberkesanan Kaunseling Kelompok Pemusatan Insan, Rasional EMotif TIngkah Laku dan Psikologi Kognitif ad-Din ke atas Tahap Tekanan, Kepuasan Kerja, Strategi Berdaya TIndak dan Sokongan Sosial Guru. Bangi: Universiti Kebangsaan Malaysia.

Shalini M. Sinniah \& Mohd. Jasmy Abd. Rahman. (2018). Faktor-faktor yang Mempengaruhi Stres Di Kalangan Guru. Prosiding Seminar Kebangsaan Majlis Dekan Pendidikan Universiti Awam (pp. 1055-1064). Kuala Terengganu: Universti Sultan Zainal Abidin.

Shamir, B., \& Lapidot, Y. (2003). Shared leadership in the management of group boundaries: A study of expulsions from officers' training courses. In C. L. (Eds.), Shared leadership: Reframing the hows and whys of leadership (pp. 235-249). Thousand Oaks: C.A: Sage.

Sinéad Brennan. (2016). Leadership Development through a Constructive Developmental Lens. Dublin, Ireland: Dublin City University . 
Syarifah Hanum Binti Ali, Arsiah Binti Bahron. (2013). Is Motivation a Mediating Factor Between Job Design and Job Performance. Asian Academy of Applied Business \& Universiti Malaysia Sabah (pp. 1-11). Bandung: AAAB.

Tan Sri Dato' Hj Muhyiddin. (2015). Perutusan tahun baharu 2015. Muat turun daripada http://www.moe.gov.my:

http://www.moe.gov.my/cms/upload_files/articlefile/2015/articlefile_file_003752.pdf

Wood, M. (2005). Determinants of Shared Leadership in Management Teams. International Journal of Leadership Studies, 1(1), 64-85.

Yukl, G.A. (2006). Leadership in Organizations (6th ed.). New Jersey: Pearson/ Prentice Hall.

Zamani, A., \& Talatapeh, M. B. B. (2014). Discussion of the motivation in the islamic and non-islamic worlds. Journal of Applied Environmental and Biological Sciences, 4(4), 68-73.

Zarapi Bin Mat Yacob, Zuraidah Abdullah. (2015). Kesan Gaya Kepimpinan Pengetua Wanita Terhadap Tahap Stres Guru. Pendidikan (The Educational Leader), 3, 123-137. 